\title{
ARTIGOS
}

\section{O IMPACTO DA VEGETAÇÃO URBANA NO CONFORTO TÉRMICO NA ESCALA LOCAL DO DISTRITO FEDERAL - DF.}

THEIMPACTOFURBAN VEGETATION ON THERMAL COMFORTIN THE LOCALSCALEIN FEDERAL DISTRICT (DF) OF BRAZIL

\author{
BÁRBARA GOMES SILVA, M.SC. UNB \\ CAIO FREDERICO E SILVA, Dr. UNB
}

\begin{abstract}
RESUMO
Em um mundo cada vez mais urbano, a vegetação mostra-se como uma das principais contribuintes para o aumento do conforto térmico no microclima. O objetivo deste estudo é analisar o impacto do acréscimo de vegetação urbana no conforto térmico na escala local do Distrito Federal. Os procedimentos metodológicos dividem-se em três etapas: (1) modelam-se dois cenários para a Zona Climática Local 3, com o software ENVI-met 4.4.4, o cenário original e com acréscimo de vegetação (hipotético); (2) simula-se o microclima para diferentes horários do dia no período quente-seco e (3) geram-se gráficos de manchas referentes ao parâmetro Temperatura Fisiológica Equivalente (PET), à temperatura do ar e velocidade dos ventos. Os resultados apontam que às 9 e 15 horas a vegetação disposta de forma linear proporciona maior conforto térmico do que dispostas em grupos. Às 21 horas, apesar de não haver alteração na percepção térmica, há a amenização da temperatura do ar em até $1^{\circ}$ C, o que é benéfico para o microclima.
\end{abstract}

PALAVRAS CHAVE: Zona Climática Local; Simulação Computacional; Vegetação Urbana; Microclima; Temperatura Fisiológica Equivalente

\begin{abstract}
Urban vegetation contributes to the increase of thermal comfort on the microclimate scale. The objective is to analyze the impact of adding urban vegetation on thermal comfort at the local level of the Federal District. The methodological procedures have three phases: (1) modeling of two scenarios for the Local Climate Zone 3, by ENVI-met software (scientific version 4.4.4), the original scenario and adding vegetation (hypothetical). (2), the microclimate is simulated for different times of the day for the hot-dry period and (3), stain graphics are generated for the parameter Physiological Equivalent Temperature (PET), air temperature and wind speed. The results show that at 9 am and $15 \mathrm{pm}$ the vegetation arranged linearly provides greater thermal comfort than arranged in groups. At $9 \mathrm{pm}$, although there is no change in thermal perception, there is an easing of the air temperature in up to $1^{\circ} \mathrm{C}$, which is beneficial for the microclimate.
\end{abstract}

KEY WORDS: Local Climate Zones; Computer Simulation; Intra-urban Vegetation; Microclimate; Physiological Equivalent Temperature 


\section{INTRODUÇÃO}

Num contexto de mudanças climáticas, a preservação dos elementos ambientais no contexto urbano como corpos d'água e massas vegetadas são excelentes estratégias de resiliência urbana, Torna-se ainda mais essencial a preservação do meio ambiente num contexto em que o mundo se torna mais urbano, com mais $70 \%$ da população global vivendo nas cidades até 2050 (fonte).

O processo de urbanização, que tem se intensificado com o aumento da população global, naturalmente requer uma redução dos elementos ambientais. A paisagem da cidade torna0se árida, seca e com baixa qualidade do ar, o que impacta diretamente da qualidade de vida da população urbana, aliado a isto, a falta de vegetação urbana aliada intensificam o desconforto térmico. Isso ocorre porque a cobertura do solo, a vegetação e a topografia são os principais responsáveis pelas alterações referentes ao clima quando se discute a escala microclimática (ROMERO, 2011), e são elementos fortemente alterados pela ação humana.

Neste contexto, a demanda de estudos relacionados ao microclima urbano vem crescendo, a fim de encontrar soluções que consigam mitigar os problemas microclimáticos, contribuindo com uma cidade mais resiliente. Além disto, a atual disponibilidade de ferramentas computacionais que facilitam esta analise urbana pode ser uma grande esperança na tentativa de comprovar a eficácia e o impacto dos elementos naturais no meio urbano.

Dentre tantos aspectos que podem afetar o microclima urbano, a vegetação se destaca, visto que são muitos os estudos que comprovam seus benefícios para o meio ambiente e a população (MORO, 1976; ABREU-HARBICH e LABAKI, 2010; LÓIS, LABAKI e SANTOS, 2011; LABAKI et al., 2011; SHINZATO e DUARTE, 2018 FERREIRA e DUARTE, 2019). Segundo Labaki et al. 2011, a vegetação proporciona benefícios relacionados ao conforto térmico no ambiente construído.

Em climas tropicais, Silva (2009) afirma que a vegetação é fundamental para a manutenção do microclima quando utilizada de forma adequada. Além disso, ela capta grande quantidade de $\mathrm{CO} 2$, auxiliando nas estratégias de mitigação das mudanças climáticas (RIBEIRO, BORGO, \& MARANHO, 2013). Aliado a isto, Szeremeta e Zannin (2013) afirmam que as áreas verdes podem contribuir para a saúde e o bem-estar da população, pois estimulam a prática de exercícios.

A falta de informações climáticas locais que auxiliem em tomadas de decisões mais precisas e individualizadas afeta a qualidade do planejamento urbano. Muitos planos diretores, por exemplo, são genéricos ao proporem a implantação de áreas arborizadas. Este contexto leva os profissionais envolvidos com o planejamento urbano como o arquiteto, paisagista, geógrafo, entre outros, ao equívoco quanto às decisões de conforto térmico. Para isso, torna-se necessária a compreensão da configuração da paisagem urbana e das características climáticas, levando em consideração a peculiaridade de cada espaço.

Assim, Stewart e Oke (2012) propõem um sistema de classificação do clima e da paisagem urbana e rural em microescala, as Zonas Climáticas Locais (ZCL), que permitem visualizar e investigar, de forma mais eficiente, a realidade climática dessas áreas. Esta metodologia vem sendo constantemente utilizada para compreender a relação de diversos aspectos da cidade com o clima urbano, como o adensamento populacional, as ilhas de calor, o uso e ocupação do solo (CARDOSO, 2015; ZHAOA et al., 2018, MONTEIRO, 2018; SOEIRA, 2019; SILVA, 2020).

O conforto térmico é uma percepção individual que implica um senso neutro para o corpo em um ambiente específico (Lin, 2009), não sendo necessário esfriar ou aquecer a temperatura do ar, a umidade ou a velocidade do vento. Em sua norma 55, a Sociedade Americana de Engenheiros de Aquecimento, Refrigeração e Ar Condicionado (ASHRAE, 2010) afirma que o conforto térmico é uma "condição mental que expressa satisfação com o ambiente térmico e é avaliada por avaliação subjetiva" (p. 3) Nesse sentido, a troca de energia térmica resulta nas condições térmicas do ambiente (Costa, 1974).

Como muitas das estratégias de conforto térmico podem ser desenvolvidas por meio de simulações computacionais, os autores decidiram usar essa abordagem para avaliar o impacto da vegetação no ambiente construído.

A maioria dos estudos nesse campo, especialmente em climas quentes, concentra-se no desempenho do edifício e de seus sistemas de refrigeração (Olivieria, Olivieri, \& Neila, 2014). No entanto, Reinhart e Davila (2016) desenvolveram uma proposta de compressão climática para lançar estratégias de mitigação, e Panchen et al. (2014) destacaram o papel da vegetação nos estudos de sazonalidade climática, e essa é a discussão promovida nesta pesquisa.

Neste sentido, este trabalho avalia o impacto da vegetação na escala local. Para isso, analisa comparativamente a contribuição do acréscimo de vegetação urbana para o conforto térmico, na escala local do Distrito Federal do Brasil, portanto, no contexto climático do clima tropical de altitude, na cidade de Brasília.

\section{ANALISE DO VERDE URBANOS COM O ENVI-MET}

Muitas pesquisas dedicam seus objetivos a entender como o desenvolvimento urbano e a falta de vegetação natural contribuem para o aumento da temperatura nas 
cidades. Alguns estudos discutem a relação entre a vegetação como meio de promover o conforto térmico em um contexto ambiental. A maioria desses estudos utilizou o ENVI-met como modelo de avaliação. Os autores selecionados têm diferentes tipos de pesquisa em diferentes contextos climáticos e de escala.

A escala das ilhas urbanas de calor (UHI) oferece pesquisas relevantes em dois contextos climáticos diferentes. Maleki e Mahdavi (2016) discutem estratégias de mitigação usando um modelo de microclima urbano tridimensional. Em seu estudo, eles investigaram os efeitos da variação das propriedades físicas e geométricas do tecido urbano no microclima urbano e no conforto térmico ao ar livre usando o ENVI-met. Os autores concluíram que resultados que aumentam a quantidade de vegetação e pavimentos permeáveis podem resfriar a temperatura do ar em até $3 \mathrm{~K}$.

Em outro clima, Razzaghmanesh, Beecham e Salemi (2016) apresentam uma investigação experimental nos vários níveis climáticos. Eles usam simulação na micro e macro escala de um ambiente urbano típico na África do Sul, avaliando o potencial de mitigação do efeito UHI na cidade de Adelaide. Eles discutem a mudança de um ambiente urbano e a substituição de superfícies vegetadas por materiais com baixo teor de albedo é uma das razões para o aumento da temperatura em um ambiente urbano e, consequentemente, também uma das causas essenciais dos efeitos de UHI. Os resultados também mostraram que eles têm efeitos significativos de resfriamento no verão e podem se comportar como uma camada de isolamento para manter os edifícios mais quentes no inverno. Finalmente, os autores afirmam que o uso de paredes verdes e árvores de rua, juntamente com a adoção de materiais com alto índice de albedo, é recomendado para alcançar a eficiência ideal em termos de redução da temperatura urbana e mitigação dos efeitos da UHI.

Pastore, Corrao e Kvols Heiselberg (2017) mostram uma nova metodologia usando um micro-banco para uma avaliação em escala de construção, vinculando o software ENVI-met ao programa de simulação de energia de construção EnergyPlus. Os autores desenvolveram um método para analisar a influência das plantas nos microclimas urbanos para aumentar a temperatura externa e interna. Além disso, este método permite avaliar os benefícios de diferentes soluções técnicas aplicadas aos edifícios. As descobertas desses autores indicaram uma redução significativa em ambas as áreas, nas temperaturas externa e interna. Seu trabalho destacou a importância de abordagens de várias e várias escalas para investigações de alta precisão sobre o desempenho térmico de edifícios.
Morakinyo et al. (2019) apontam as técnicas passivas, pois fachadas verdes podem ser uma ótima estratégia para melhorar o ambiente térmico ao ar livre e reduzir o uso de energia em ambientes fechados. Especificamente, em cidades de alta densidade como Hong Kong, a área de superfície dos edifícios é muito maior do que as áreas de telhado e solo combinadas, oferecendo uma plataforma vertical para o esverdeamento. Os autores usaram a simulação do modelo ENVI-met para entender o potencial resfriamento do ar e a melhoria do conforto térmico de uma vizinhança de densidades variadas. Eles descobriram que 30 a 50\% das fachadas no ambiente urbano de alta densidade de Hong Kong devem ser esverdeadas para causar potencialmente uma redução de cerca de $1^{\circ} \mathrm{C}$ na temperatura do ar durante o dia e a noite. Ao mesmo tempo, ajuda a melhorar o conforto térmico para pedestres durante o dia em pelo menos uma classe termal.

Ahmad, Babak, Davoud e Suhardi (2019) discutem como o clima local afeta negativamente os UHIs e o conforto térmico ao ar livre. Esses autores apresentam estudos recentes que enfocam os efeitos de espaços verdes e plantas no microclima e no conforto térmico dos últimos anos. Como metodologia, esta pesquisa aborda diferentes parâmetros, como propriedades físicas das plantas, localização e cobertura vegetal, densidades de plantio e densidade de copas, elemento da planta, tipo de folha, padrões e arranjos de plantio e albedo. Os resultados destacaram que vários fatores com impacto no efeito de resfriamento das plantas ainda não haviam recebido atenção adequada em estudos anteriores.

As pesquisas de Zölch, Maderspacher, Wamsler e Pauleit (2016) concentram-se no entendimento do desempenho da infraestrutura verde urbana (UGI). Esses autores discutem como faltam informações comparáveis sobre o desempenho de diferentes tipos de UGI para moderar esses impactos. Esta pesquisa investiga como diferentes tipos e quantidades de UGI (ou seja, árvores, telhados verdes e fachadas verdes) afetam o conforto térmico dos pedestres. $O$ estudo mostra os valores fisiológicos de temperatura equivalente (PET) em 2,4 K. No entanto, isso pode ser bastante reduzido por diferentes cenários de UGI. O artigo provou que o plantio de árvores teve o impacto mais positivo, com uma redução média de 13\% no PET, em comparação com a vegetação existente. Especificamente, em fachadas verdes, tem efeitos atenuantes de 5 a $10 \%$. Outros resultados indicam que o aumento da participação na cobertura verde também não corresponde diretamente à magnitude da redução do PET. 


\section{PROCEDIMENTOS METODOLÓGICOS}

Como método, utiliza-se da Zona Climática Local 3 do Distrito Federal (DF) com base na Temperatura Fisiológica Equivalente - PET (HÖPPE, 1999) e da temperatura do ar, e é resultado da dissertação de mestrado de Silva (2020) que classifica as ZCLs de Regiões Administrativas do DF e desenvolve um método de avaliação da contribuição da vegetação em ZCLs por meio de simulações computacionais.

$\mathrm{O}$ método deste trabalho consiste na modelagem e simulação computacional, da ZCL 3 classificada por Silva (2020), considerando dois cenários: o cenário original, que representa a ZCL como se encontra hoje; e o cenário hipotético, com acréscimo de vegetação em áreas livres e canteiros centrais, conforme critérios apresentados por Lóis, Labaki e Santos (2011) e Silva (2009).

No âmbito do software, é modelada a área de 160.000 $\mathrm{m}^{2}$, resultante de um quadrilátero de $400 \mathrm{~m}$, configurando o cenário. Após a simulação computacional, faz-se a extração dos gráficos de manchas com os resultados de PET, temperatura do ar e velocidade dos ventos para às 9 , $15 \mathrm{e}$ 21 horas para o período climático quente-seco do Distrito Federal, com o auxílio dos plugins Biomet e Leonardo.

\subsection{Modelagem}

A ZCL 3 é uma área residencial com construções de até 3 andares, possui bastante área impermeável e poucas árvores, que estão localizadas principalmente na via central. $A$ área de estudo localiza-se na Região Administrativa XXI - Riacho Fundo II no DF (Figura 03), portanto, utiliza-se a latitude e longitude de Brasília, $-15,78^{\circ}$ e $-47,93^{\circ}$, respectivamente, e localização acima do nível do mar de 1.172 metros.

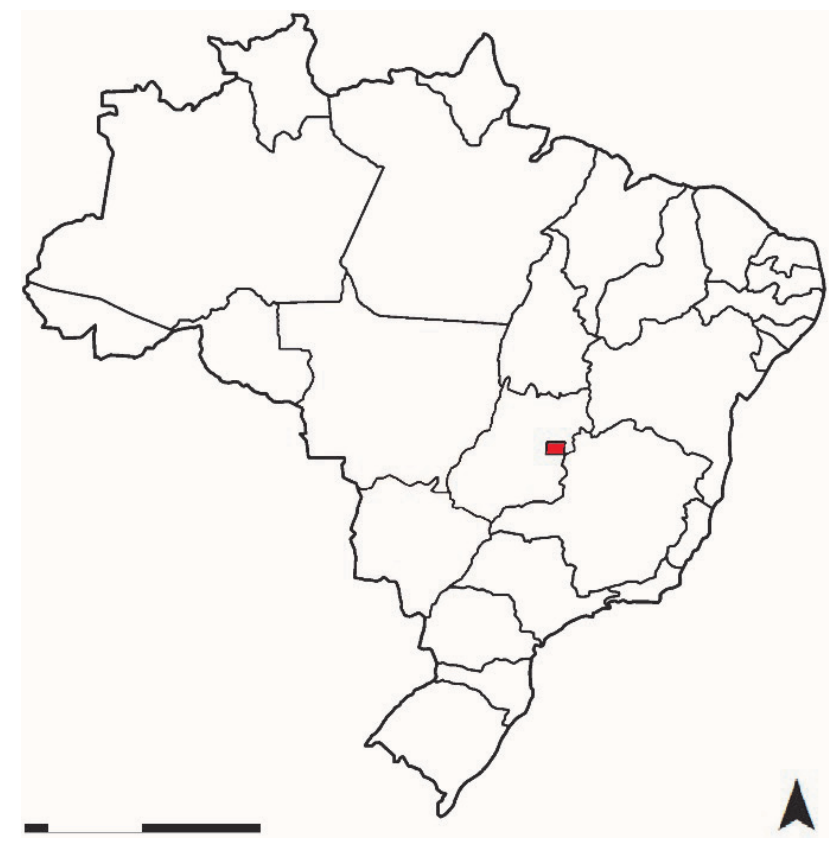

Figura 02 - Localização da DF no contexto nacional Fonte: 0 s autores, 2020

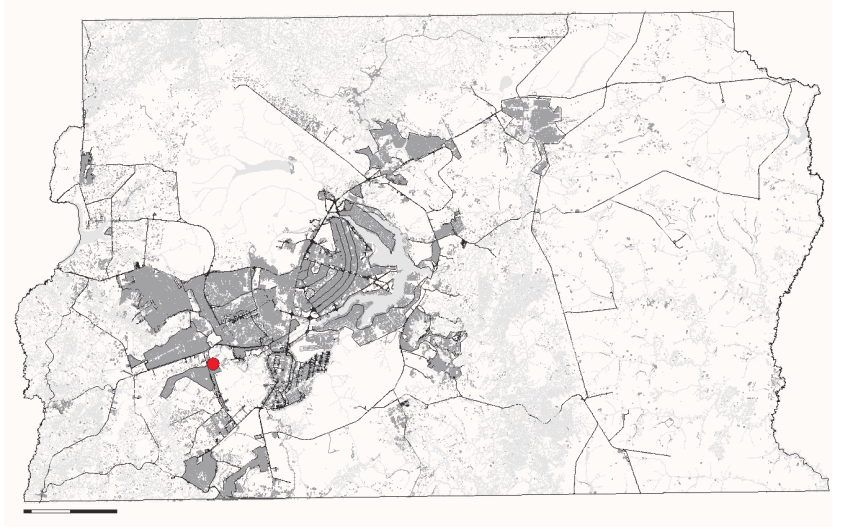

Legenda: - Área de estudo

Figura 03 - Localização da ZCL 3 no contexto do DF Fonte: 0 s autores, 2020

Para a modelagem dos cenários, considera-se as dimensões das edificações, os materiais de cobertura do solo, a quantidade de vegetação, bem como sua distribuição no espaço e faz-se a simplificação do cenário. Em seguida, posiciona-se a área da forma mais ortogonal

Figura 01 - Fluxo das etapas metodológicas

Fonte: 0 s autores, 2020 
possível, o que facilita a modelagem no software, que é realizada em uma malha quadriculada de 100×100 grids, onde cada grid corresponde a 4 metros. Para correção do norte geográfico, é necessário inserir o valor do grau de rotação do Norte no ENVI-met (Quadro 1).

\begin{tabular}{|l|l|l|}
\hline $\begin{array}{l}\text { Imagem satélite do } \\
\text { cenário original }\end{array}$ & $\begin{array}{l}\text { Cenário original } \\
\text { simplificado }\end{array}$ & \\
\hline & & \\
\hline
\end{tabular}

Quadro 01 - Grau de rotação do Norte

Fonte: Geoportal,2019

Assim, modelam-se os dois cenários, sendo que estes são diferenciados pela área permeável e impermeável, considerando as características da geometria urbana, dos materiais de cobertura do solo, além da quantidade de vegetação. Os cenários são diferenciados pela quantidade de vegetação, considerando as características da geometria urbana e dos materiais de cobertura do solo.
Esquema do cenário original

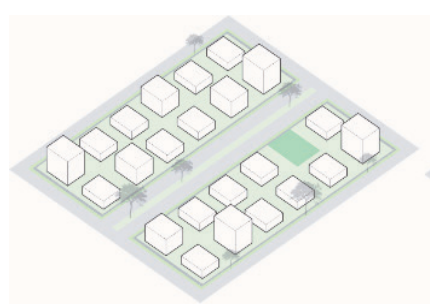

Esquema do cenário com acréscimo de vegetação
Figura 04 - Diagrama dos cenários de modelagem microclimática de uma ZCL Fonte: 0 s autores, 2020

Há o acréscimo de vegetação no canteiro central da via principal e nas calçadas de forma linear, onde há maior fluxo de veículos e pessoas. Além disso, adiciona-se vegetação arbórea agrupada nos espaços livres, como praças.

\begin{tabular}{|l|l|}
\hline $\begin{array}{l}\text { Modelagem do cenário } \\
\text { original }\end{array}$ & $\begin{array}{l}\text { Modelagem do cenário com } \\
\text { acréscimo de vegetação }\end{array}$ \\
\hline
\end{tabular}

Quadro 02 - Modelagem do cenário original e com acréscimo de vegetação Fonte: 0 s autores, 2020
Os materiais utilizados na modelagem devem se aproximar das características reais dos materiais encontrados na área, sendo que neste estudo define-se: grama (grass), asfalto (asphalt), pavimento de concreto cinza (concrete pavement gray) para calçadas e solo argiloso (loamy soil) para solo exposto e abaixo de edificações. Além disso, definem-se os materiais de parede e cobertura das edificações, sendo: parede de concreto (concrete wall) e telhado de material cerâmico (roofing: terracota), considerando que as coberturas existentes são, em sua maioria, telhado colonial.

\subsection{Simulação computacional microclimática}

A simulação computacional microclimática do meio urbano consiste em uma simplificação de cenários reais que pretende representar as características dos elementos que constituem o espaço, porém, é importante ressaltar que "o mundo real se mostra tão complexo que é impossível reproduzir todas as suas características, as suas relações funcionais e todo o conjunto de interdependências" (ANJOS, 2008).

Assume-se que esta pesquisa estuda a camada intraurbana simulando as interações edifício-meio urbano. Neste sentido, adota-se o software ENVI-met 4.4.4 para simulações referentes ao conforto térmico urbano visto que este é o único programa que considera a fisiologia da vegetação para simular dados de conforto térmico urbano.

Existem dois métodos para inserção de dados climáticos para o ENVI-met 4.4.4: Simple Forcing e Full Forcing. No método Simple Forcing é necessária a coleta, pelo próprio pesquisador, de cada dado climático da cidade onde localiza-se a área de estudo, sendo: velocidade e direção do vento, temperatura do ar e umidade relativa do ar mínimas e máximas para o dia simulado; dessa forma, o software forçará o comportamento dos parâmetros climáticos durante um dia inteiro. Já no método Full Forcing, que força o comportamento do vento, temperatura, umidade e cobertura de nuvens em intervalos de 30 minutos para o período de até 1 ano, é possível utilizar um arquivo climático já configurado, por exemplo, em formato "EPW" (Energy Plus Weather) obtido no portal do EnergyPlus, para a cidade onde localiza-se a área de estudo, sendo que esta opção diminui as chances de erro, visto que não há a necessidade de que o próprio pesquisador insira os dados individualmente. Assim, neste estudo opta-se pelo uso do método Full Forcing.

Os dados climáticos para simulação são configurados a partir do arquivo climático de formato EPW para a Região Administrativa de Brasília, sendo esta a cidade com dados meteorológicos registrados mais próxima da área de estudo. Assim, cria-se o arquivo em formato FOX nomeado como "Brasília_Período-Quente-Seco.fox". 


\subsection{Extração de dados}

Os dados das simulações computacionais são extraídos por meio dos plugins Biomet e Leonardo para o dia 29 de setembro de 2018, o mais quente do ano, nos horários de 09, 15 e 21 horas, estes indicados pela Organização Meteorológica Mundial (OMM) para registro de dados meteorológicas, e são apresentados em forma de gráficos de manchas.

Para a análise dos dados de conforto, utiliza-se o parâmetro de conforto térmico Physiological Equivalent Temperature (PET), ou Temperatura Fisiológica Equivalente quando traduzido para português, desenvolvido por Höppe (1999), que considera a fisiologia do corpo humano em condições de estabilidade e as variáveis climáticas da área de estudo para avaliar o balanço térmico do corpo conforme Tabela 1, além da temperatura do ar e velocidade dos ventos.

O sofwatre ENVI-met 4.4.4 utiliza como padrão para extração de dados de PET, um ser humano com as características definidas pela ISO 7730/2005: homem com 35 anos de idade, $75 \mathrm{~kg}$, altura de 1,75m e taxa metabólica igual a $86,21 \mathrm{~W} / \mathrm{m}^{2}$.

\begin{tabular}{|c|c|c|}
\hline PET & $\begin{array}{l}\text { Percepçáa } \\
\text { térmica }\end{array}$ & $\begin{array}{l}\text { Grau de estresse } \\
\text { fisloløglco }\end{array}$ \\
\hline$<4$ & Frio extremo & $\begin{array}{l}\text { Estresse por frio } \\
\text { extremo }\end{array}$ \\
\hline $4-8$ & Muito frio & $\begin{array}{l}\text { Estresse por frio } \\
\text { elevado }\end{array}$ \\
\hline $8.1-13$ & Frio & Estresse por frio \\
\hline $13.1-18$ & Levemente frio & $\begin{array}{c}\text { Estresse por frio } \\
\text { moderado }\end{array}$ \\
\hline $18.1-23$ & Confortăvel & Sem estresse térmico \\
\hline $23.1-29$ & $\begin{array}{l}\text { Levemente } \\
\text { calor }\end{array}$ & $\begin{array}{c}\text { Estresse por calor } \\
\text { moderado }\end{array}$ \\
\hline $29.1-35$ & Calor & Estresse por calor \\
\hline $35.1-41$ & Muito calor & $\begin{array}{l}\text { Estresse por calor } \\
\text { elevado }\end{array}$ \\
\hline$>41$ & Calor extremo & $\begin{array}{l}\text { Estresse por calor } \\
\text { extremo }\end{array}$ \\
\hline
\end{tabular}

Tabela 01 - Valores de PET

Fonte: os autores, 2020

\section{RESULTADOS}

De uma maneira geral, o resultado do acréscimo de vegetação na ZCL foi positivo.

Observa-se que às 9 horas (Quadro 03) o cenário original apresenta áreas de leve calor localizadas na via principal, nas calçadas entre os conjuntos residenciais e em áreas livres. Já no cenário com acréscimo de vegetação há melhora do conforto térmico, principalmente no canteiro central da via principal, onde há arborização com distanciamento de 4 metros entre as copas. Não houve melhora do conforto nas calçadas às 09h.

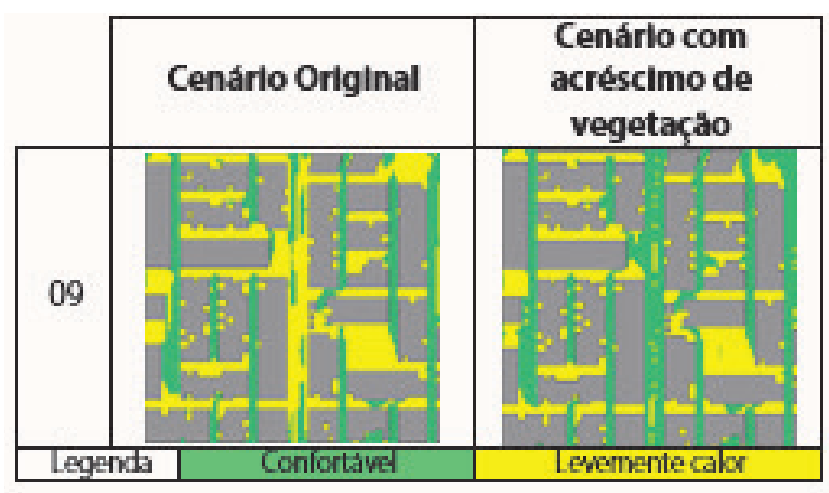

Quadro 03 - Resultados de Temperatura Fisiológica Equivalente para às $09 \mathrm{~h}$ Fonte: 0 s autores, 2020

A praça entre os conjuntos residenciais onde houve o acréscimo de árvores continua apresentando leve calor, podendo ser justificada pela pouca alteração na velocidade dos ventos (Quadro 04), que continua a apresentar valores entre 0 e $1 \mathrm{~m} / \mathrm{s}$. A configuração do espaço, praça rodeada por conjuntos de residências de até 3 andares, pode ter contribuído para esse resultado, pois forma uma barreira para o vento. Além disso, as árvores acrescidas estão dispostas em conjunto, configurando uma espécie de pequeno bosque, sendo um obstáculo para a ventilação.

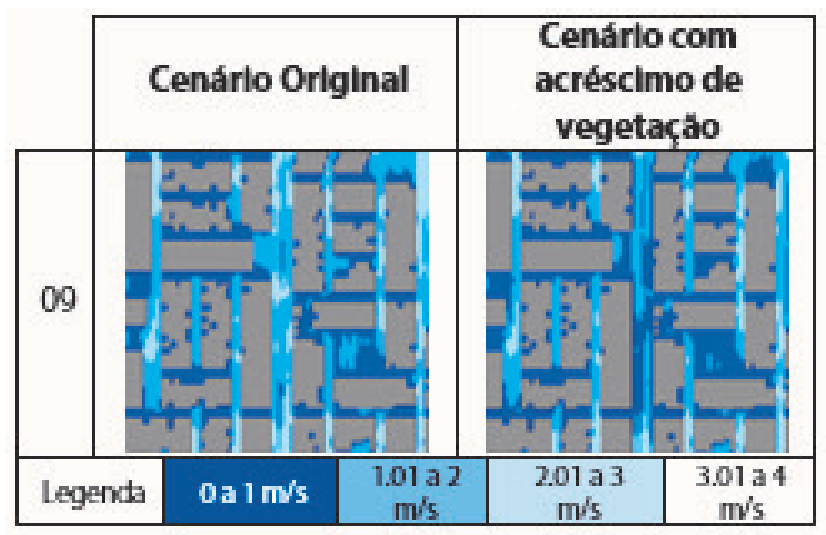

Quadro 04 - Resultados de velocidade dos ventos para às $09 \mathrm{~h}$ Fonte: 0 s autores, 2020

A via central, apesar do acréscimo de árvores causar a diminuição da velocidade do vento, apresenta conforto térmico. Mesmo com a velocidade reduzida, observam-se valores entre 1 e $3 \mathrm{~m} / \mathrm{s}$. As árvores estão dispostas de forma linear, o que pode ter contribuído para que a passagem do vento não fosse completamente impedida.

Para às $15 \mathrm{~h}$ (Quadro 05) percebe-se apenas áreas com muito calor ou calor extremo, tanto no cenário original quanto com acréscimo de vegetação, porém a vegetação melhora o conforto térmico nos espaços onde há a implantação de árvores, incluindo a praça entre as residências e nas calçadas. 


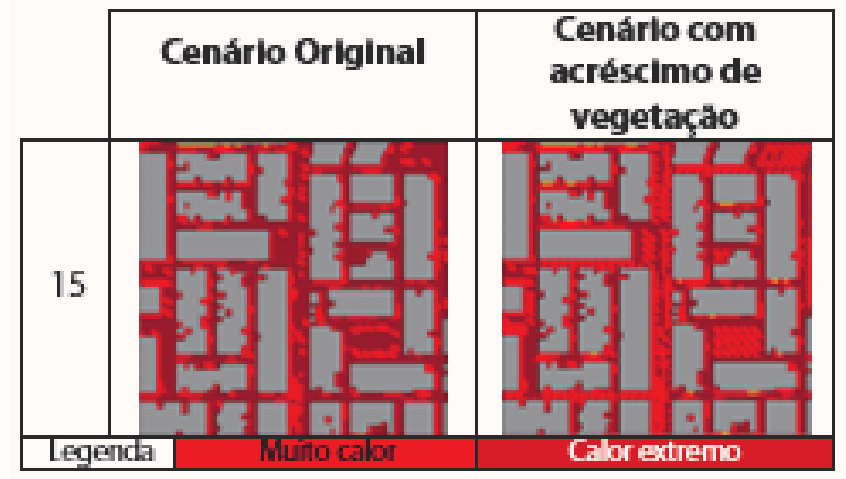

Quadro 05 - Resultados de Temperatura Fisiológica Equivalente para às $15 \mathrm{~h}$ Fonte: 0 a autores, 2020

Às 21h não há alteração quanto ao grau de estresse fisiológico (Quadro 06), sendo que os dois cenários apresentam leve calor, o que não significa que não houve alguma melhora, visto que a Temperatura Fisiológica Equivalente a "levemente calor" encontra-se entre $23.1^{\circ} \mathrm{C}$ e $29^{\circ} \mathrm{C}$.

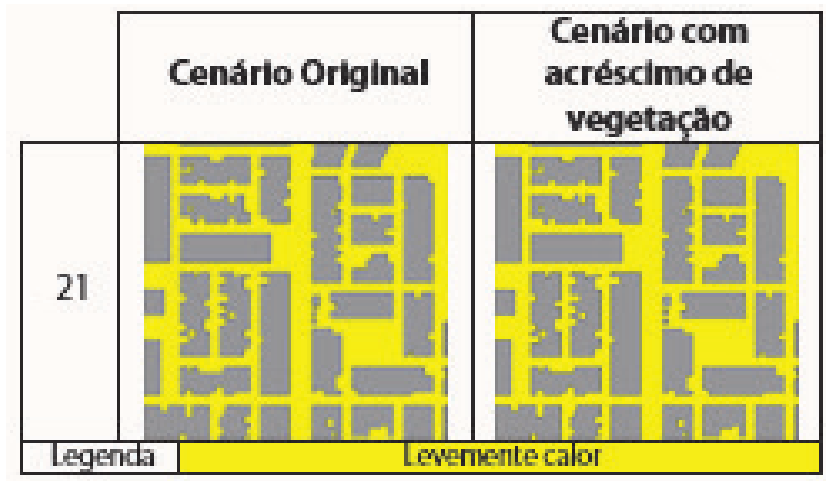

Quadro 06 - Resultados de Temperatura Fisiológica Equivalente para às $21 \mathrm{~h}$ Fonte: 0 autores, 2020

Assim, analisa-se a temperatura do ar (Quadro 07) e observa-se que houve a amenização do calor em algumas áreas com o aumento da vegetação arbórea, principalmente na via central, com diferenças de até $1^{\circ} \mathrm{C}$.

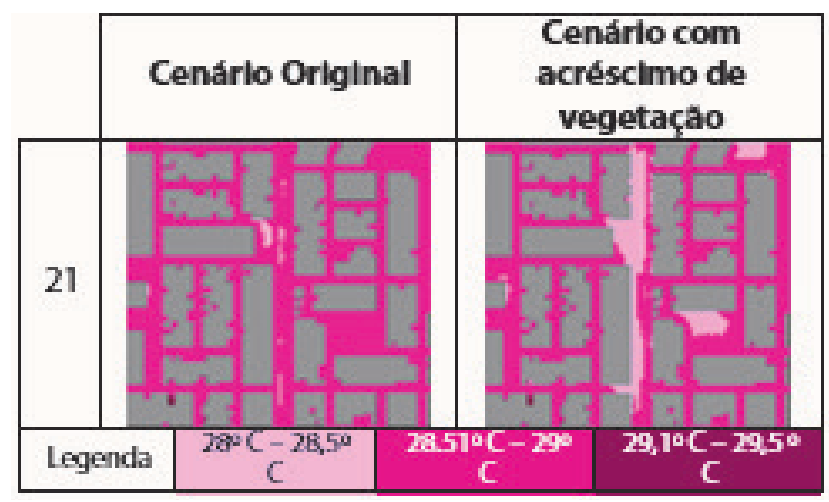

Quadro 07 - Resultados de temperatura do ar para às $21 \mathrm{~h}$ Fonte: 0 autores, 2020
A ZCL 3, com característica residencial de baixa permeabilidade do solo, apresentou em seu cenário original Temperatura Fisiológica Equivalente máxima de $48,2^{\circ} \mathrm{C}$ e mínimo de $21^{\circ} \mathrm{C}$. $\mathrm{O}$ acréscimo de vegetação significou uma amenização de até $3,78^{\circ} \mathrm{C}$, diminuindo o grau de estresse fisiológico do pedestre.

\section{CONCLUSÃO}

Conclui-se que o acréscimo de vegetação na Zona Climática Local 3 melhora o conforto térmico em $3,78^{\circ} \mathrm{C}$, principalmente onde as árvores encontram-se dispostas de forma linear, como ocorre nos canteiros centrais às 9 horas. Quando dispostas em grupos, formando uma espécie de bosque, a vegetação cria uma barreira que dificulta a ventilação, melhorando o conforto apenas próximo à árvore.

No horário mais quente do dia, às $15 \mathrm{~h}$, a vegetação ameniza o desconforto térmico, mesmo que ainda apresente resultados de percepção térmica equivalentes a muito calor, tanto em áreas onde a vegetação encontra-se disposta em grupos, quanto de forma linear.

O PET é dado por meio de intervalos que variam entre $4^{\circ} \mathrm{C}$ e $6^{\circ} \mathrm{C}$, sendo assim, às 21 horas não é possível observar com clareza os efeitos da vegetação na amenização do calor, sendo necessária a análise de dados complementares, como a temperatura do ar. Neste horário, percebe-se, então, que apesar de não haver alteração na percepção térmica, há a amenização da temperatura do ar devido ao acréscimo de vegetação, o que é benéfico para o microclima, visto a necessidade de amenização das alterações climáticas nas cidades.

O método de simulação computacional mostra-se adequado para a análise da contribuição da vegetação no microclima urbano, pois permite a extração de diversos dados que se complementam. Assim, é possível compreender as possíveis causas para os resultados apresentados.

\section{REFERÊNCIAS}

ABREU-HARBICH, L. V., \& LABAKI, L. C. (dezembro de 2010). Conforto térmico propiciado por algumas espécies arbóreas: avaliação do raio de influência através de diferentes índices de conforto. Ambiente Construído, 10(4), 103-117.

Ahmad, H., Babak, A., Davoud, Z., \& Suhardi, B. (Agosto de 2019). Assessing the thermal comfort effects of green spaces: A systematic review of methods, parameters, and plants' attributes. Sustainable Cities and Society.

ANJOS, R. S. (2008). Dinâmica Territorial: cartografia, monitoramento e modelagem. Brasília: Mapas Editora 
\& Consultoria.

ASHRAE. (2010). ANSI/ASHRAE Standard 55-2010: Thermal Environmental Conditions for Human Occupancy. American Society of Heating, Refrigerating and Air-Conditioning Engineers, Inc., Atlanta.

BRUSE, M., \& FLEER, H. (outubro de 1998). Simulating SurfacePlant-Air Interactions Inside Urban Environments with a Three Dimensional Numerical Model. Environmental Software and Modeling, 13(3), 373-384.

CARDOSO, R. S. (2015). Classificação De Potenciais Unidades Climáticas Em Presidente Prudente - SP. Dissertação (Mestrado em Geografia). Faculdade de Ciências e Tecnologia, Universidade Estadual Paulista, São Paulo.

Costa, E. C. (1974). Física aplicada à construção: Conforto térmico. São Paulo: Blücher.

FERREIRA, L. S., \& DUARTE, D. H. (março de 2019). Exploring the relationship between urban form, land surface temperature and vegetation indices in a subtropical megacity. Urban Climate, 27, 105-123.

HÖPPE, P. (1999). The Physiological Equivalent Temperature: a universal index for the biometeorological assessment of the thermal environment. International Journal of Biometeorology, 43, 71-75.

LABAKI, L. C., SANTOS, R. F., BUENO-BARTHOLOMEI, C. L., \& ABREU, L. V. (2011). Vegetação e Conforto Térmico Em Espaços Urbanos Abertos. Fórum Patrimônio, 4(1), 23-42.

Lin, P. (2009). Thermal perception, adaptation, and attendance in a public square in hot and humid regions. Building and Environment, pp. 2017-2026.

LÓIS, E., LABAKI, L., C., \& SANTOS, R. F. (junho de 2011). Efeitos de diferentes estruturas de vegetação ciliar sobre as variáveis de microclima e a sensação de conforto térmico. Revista do Instituto Florestal, 23(1), 117-136. MALEKI A., M. A. (2016). EVALUATION OF URBAN HEAT ISLANDS MITIGATION STRATEGIES USING 3DIMENTIONAL URBAN MICRO-CLIMATE MODEL ENVI-MET. ASIAN JOURNAL OF CIVIL ENGINEERING (BUILDING AND HOUSING), 17(3), pp. 357-371.

MONTEIRO, V. S. (2018). Zonas Climáticas Locais e a relação com a morfologia urbana. Estudo de caso: Campinas - SP. (Dissertação de mestrado). Programa de Pós-graduação em Sistemas de Infraestrutura Urbana - Pontifícia Universidade Católica de Campinas, Campinas.

Morakinyoa, T. E., Lai, A., Ka-Lun Lau, K., \& Ng, E. (Janeiro de 2019). Thermal benefits of vertical greening in a high-density city: Case study of Hong Kong. Urban Forestry \& Urban Greening, pp. 42-55.

MORO, D. Á. (1976). As Áreas Verdes e Seu Papel na Ecologia Urbana e no Clima Urbano. Separata da Revista UNIMAR, 1, 15-20.

Olivieria, F., Olivieri, L., \& Neila, J. (Julho de 2014). Experimental study of the thermal-energy performance of an insulated vegetal façade under summer conditions in a continental mediterranean climate. Building and Environment, pp. 61-76.

Panchen, Z., Primack, R., Nordt, B., Ellwood, E., Stevens, A., Renner, S., ... Davis, C. (Setembro de 2014). Leaf out times of temperate woody plants are related to phylogeny, deciduousness, growth habit and wood anatomy. New Phitology, pp. 1208-1219.

Pastore, L., Corrao, R., \& Heiselberg, P. (2017). The effects of vegetation on indoor thermal comfort: The application of a multi-scale simulation methodology on a residential neighborhood renovation case study. Energy and Buildings, pp. 1-11.

Razzaghmanesh, M., Beecham, S., \& Salemi, T. (2016). The Role of Green Roofs in Mitigating Urban Heat Island Effects in the Metropolitan Area of Adelaide, South Australia. Urban Forestry and Urban Greening, pp. 89-102.

Reinhart, C., \& Davila, C. (Fevereiro de 2016). Urban building energy modeling - A review of a nascent field. Building and Environment, pp. 196-202.

RIBEIRO, J., BORGO, M., \& MARANHO, L. (junho de 2013). Áreas protegidas de curitiba ( $p r$, brasil) como sumidouros de CO2. Floresta, 43(2), 181-190.

ROMERO, M. A. (2011). Correlação entre o microclima urbano e a configuração do espaço residencial de Brasília. Fórum Patrimônio, 4(1), 9-22.

SHINZATO, P., \& DUARTE, D. H. (junho de 2018). Impacto da vegetação nos microclimas urbanos e no conforto térmico em espaços abertos em função das interações solo-vegetação-atmosfera. Ambiente Construído, 18(2), 197-215.

SILVA, B. G. (2020). A Contribuição da Vegetaçãp intraurbana em Zonas Climáticas Locais no Distrito Federal. Dissertação de mestrado. Programa de Pósgraduação em Arquitetura e Urbanismo, Univerdidade de Brasília., Brasília.

Silva, B. G., Adário, J., \& Silva, C. F. (2019). Aplicação do Arquivo Climático na Análise do Microclima Urbano da Cidade de Juiz de Fora - Minas Gerais. ${ }^{\circ}$ Seminário de Pesquisa em Ambiente Construído, (p. 5). Juiz de Fora.

SILVA, C. F. (2009). Caminhoes Bioclimáticos: Desempenho Ambiental de Vias. (Dissertação de 
mestrado). Faculdade de Arquitetura e Urbanismo, Universidade de Brasília, Brasília.

SOEIRA, M. R. (2019). A relação entre o fator de visão do céu e a temperatura do ar em diferentes zonas climáticas locais. (Dissertação de mestrado). Programa de Pós-Graduação em Sistemas de Infraestrutura Urbana Pontifícia Universidade Católica de Campinas, Campinas.

STEWART, I. D., \& OKE, T. R. (dezembro de 2012). Local Climate Zones For Urban Temperature Studies. Bulletin of the American Meteorological Society, 1879-1900.

SZEREMETA, B., \& ZANNIN, P. H. (dezembro de 2013). A importância dos parques urbanos e áreas verdes na promoção da qualidade de vida em cidades. Ra'e Ga - O espaço geográfico em análise, 29, 177-193.

ZHAOA, C., JENSENA, J., WENGC, Q., CURRITA, N., \& WEAVERA, R. (novembro de 2018). Application of airborne remote sensing data on mapping local climate zones: Cases of three metropolitan areas of Texas, U.S. Computers, Environment and Urban Systems, 74, 175-193.

Zölcha, T., Maderspacher, J., Wamsler, C., \& Pauleit, S. (Dezembro de 2016). Using green infrastructure for urban climate-proofing: An evaluation of heat mitigation measures at the micro-scale. Urban Forestry \& Urban Greening, pp. 305-316.

\section{AGRADECIMENTOS}

Agradecemos o apoio da equipe do software ENVImet que disponibilizou a versão Student do plugin Biomet e à Fundação de Apoio à Pesquisa do Distrito Federal do Brasil (FAP-DF) pelo apoio financeiro na bolsa de Pós-doutorado do segundo autor.

\section{AUTORES}

ORCID: https://orcid.org/0000-0003-2494-7365

BÁRBARA GOMES SILVA, M.Sc. | Universidade de Brasília| Faculdade de Arquitetura e Urbanismo | Brasília, DF Brasil | Correspondência para: Quadra 06 Conjunto D Lote 24 Setor Sul, Gama - DF, 72415-304 | e-mail: barbarag.arquitetura@gmail.com

ORCID: https://orcid.org/0000-0001-8910-1841

CAIO FREDERICO E SILVA, Dr. | Universidade de Brasília| Faculdade de Arquitetura e Urbanismo | Brasília, DF Brasil | Correspondência para: Campus Darcy Ribeiro. ICC Norte FAU SN, 70910-900 | e-mail: caiosilva@unb.br

\section{COMO CITAR ESTE ARTIGO}

SILVA, Bárbara Gomes; SILVA, Caio Frederico e. O Impacto da Vegetação Urbana no Conforto Térmico na Escala Local do Distrito Federal - DF. MIX Sustentável, [S.I.], v. 6, n. 2, p. 89-98, mai. 2020. ISSN 24473073. Disponível em:<http://www.nexos.ufsc.br/index.php/ mixsustentavel>. Acesso em: dia mês. ano. doi:https:// doi.org/10.29183/2447-3073.MIX2020.v6.n2.89-98.

DATA DE ENVIO: 20/05/2020

DATA DE ACEITE: 21/05/2020 
